\title{
Precocious Alterations of Brain Oscillatory Activity in Alzheimer's Disease: A Window of Opportunity for Early Diagnosis and Treatment
}

\author{
Valentine Hamm ${ }^{1,2 *}$, Céline Héraud ${ }^{1,2}$, Jean-Christophe Cassel1,2, Chantal Mathis ${ }^{1,2}$ and \\ Romain Goutagny ${ }^{1,2 *}$
}

${ }^{1}$ Centre National de la Recherche Scientifique UMR 7364, Laboratoire de Neurosciences Cognitives et Adaptatives, Strasbourg, France, ${ }^{2}$ Université de Strasbourg, Neuropôle de Strasbourg, Strasbourg, France

\section{OPEN ACCESS}

Edited by:

Lydia Jimenez-Diaz,

University of Castilla La Mancha,

Spain

Reviewed by:

Andre Fisahn

Karolinska Institutet, Sweden Valentina Kitchigina,

Institute of Theoretical and Experimental Biophysics Russian Academy of Sciences, Russia

*Correspondence: Valentine Hamm valentinehamm@hotmail.com: Romain Goutagny goutagny@unistra.fr

Received: 30 September 2015 Accepted: 04 December 2015 Published: 21 December 2015

Citation: Hamm V, Héraud C, Cassel J-C, Mathis $C$ and Goutagny R (2015)

Precocious Alterations of Brain Oscillatory Activity in Alzheimer's Disease: A Window of Opportunity for Early Diagnosis and Treatment.

Front. Cell. Neurosci. 9:491. doi: 10.3389/fncel.2015.00491
Alzheimer's disease (AD) is the most common form of neurodegenerative dementia accounting for $50-80 \%$ of all age-related dementia. This pathology is characterized by the progressive and irreversible alteration of cognitive functions, such as memory, leading inexorably to the loss of autonomy for patients with AD. The pathology is linked with aging and occurs most commonly around 65 years old. Its prevalence $5 \%$ over 65 years of age and $20 \%$ after 80 years) constitutes an economic and social burden for $A D$ patients and their family. At the present, there is still no cure for $A D$, actual treatments being moderately effective only in early stages of the pathology. A lot of efforts have been deployed with the aim of defining new AD biomarkers. Successful early detection of mild cognitive impairment $(\mathrm{MCl}$ ) linked to $\mathrm{AD}$ requires the identification of biomarkers capable of distinguishing individuals with early stages of $A D$ from other pathologies impacting cognition such as depression. In this article, we will review recent evidence suggesting that electroencephalographic (EEG) recordings, coupled with behavioral assessments, could be a useful approach and easily implementable for a precocious detection of AD.

Keywords: Alzheimer's disease, mild cognitive impairment, recognition memory, spatial navigation memory, oscillatory activity, electroencephalography

\section{INTRODUCTION}

Alzheimer's disease $(\mathrm{AD})$ is a progressive neurodegenerative disorder that starts with mild shortterm memory deficits before progressively culminating in total loss of cognitive and executive functions. Currently, the precise etiology of the pathology is not known and there is no cure. Genetic studies (Price et al., 1998; Van Cauwenberghe et al., 2015) have identified mutations in the genes of the transmembrane amyloid peptide precursor protein (APP) and those of presenilins 1 and 2 (PS1, PS2) responsible for rare dominantly inherited early onset familial AD (FAD). Proteolytic processing of APP first by the $\beta$-site APP cleaving enzyme, followed by the PS-containing $\gamma$-secretase complex, generates amyloid- $\beta(A \beta)$ peptides that deposit in amyloid plaques. Many studies showed an increased production of more amyloidogenic A $\beta$ peptides associated with FAD-linked mutations, providing strong support for the amyloid hypothesis (Hardy and Selkoe, 2002). According to this conceptual framework, it would be the early accumulation of soluble $A \beta$ in specific brain areas that elicits abnormal patterns of neuronal activity leading to cognitive decline (Palop and Mucke, 2010). Therefore, a lot of efforts have been deployed 
in order to lower $A \beta$ levels as a possible therapy for $A D$. Various types of treatments have been tested including the use of $\gamma$-secretase inhibitors and immunization against $A \beta$. Unfortunately, these drugs were less successful than expected, inducing no improvement, or even a worsening of cognitive functions, often accompanied by drastic side-effects that preclude their use as suitable therapeutics for AD (Mikulca et al., 2014). Diverse hypothesis were put forward to explain the disappointing results obtained by current anti-A $\beta$ treatments. First, other APP fragments, like the $\beta$-carboxy terminal fragment $(\beta$-CTF; Lahiri et al., 2002; Pimplikar et al., 2010; Lauritzen et al., 2012; Tamayev et al., 2012; Goutagny et al., 2013), the amyloid intracellular domain (AICD), or the recently described CTF- $\eta$ (Willem et al., 2015), might play key roles in AD pathogenesis and associated cognitive symptoms. A second hypothesis highlights the fact that treatments were given too late in the time-course of $\mathrm{AD}$, when neuronal damages are already too extensive and irreversible. However, these two points are closely linked. We need to develop new early biomarkers, independent of the amyloid hypothesis, that do not entirely rely on $\mathrm{A} \beta$ dosage. In this article, we will review recent evidences indicating that the characterization of oscillatory activity in patients using electroencephalographic (EEG) recordings, a cost-efficient and easily implementable strategy, might represent a new opportunity for the early detection of $\mathrm{AD}$. In addition, we propose that characterization of cross-frequency coupling (CFC), a specific motif of oscillatory interactions, might represent an extremely sensitive early biomarker.

\section{BRAIN OSCILLATORY ACTIVITY}

Cognitive processes (i.e., information processing and storage by brain networks) require a highly coordinated operation of multiple neuronal groups. One likely mechanism is through the coordinated rhythmic activity of neuronal populations, which give rise to oscillations (Womelsdorf et al., 2007). These oscillations can be recorded using various techniques, such as electrocorticography, local field potential, magnetoencephalography, or EEG. Rhythmic fluctuations of electric potentials measured by these technics are generated by the spatial summation of highly synchronized post-synaptic potentials occurring in large clusters of neurons. They have an excellent temporal resolution (in the millisecond timescale) and now, new analytic methods allow locating generators of these oscillations with a decent spatial resolution even using EEG (around one voxel with the LORETA method in human EEG; Gianotti et al., 2007).

The spectral content of EEG is classically divided in five frequency bands: $\delta$ (from 1 to $4 \mathrm{~Hz}$ ), $\theta$ (4 to $7 \mathrm{~Hz}$ ), $\alpha$ (8 to $12 \mathrm{~Hz}), \beta$ (15 to $30 \mathrm{~Hz})$, and $\gamma(>30 \mathrm{~Hz})$. On a functional level, these diverse oscillations are associated with different brain states. Oscillatory activities are related to global states (i.e., $\delta$ waves are mainly present during sleep) or specific behaviors (i.e., $\beta$ rhythm is usually associated to motor tasks and is thought to reflect the activity of motor cortices; Pfurtscheller et al., 1998). Some frequency domains are more closely related to cognitive processes. First, $\theta$ oscillations are thought to play a key role in working memory processes (Sauseng et al., 2010). $\theta$ phase affects memory processing through the modulation of neuronal plasticity within hippocampal and cortical areas and plays a modulatory role in the induction of long-term-potentiation (LTP), a long lasting enhancement of synaptic efficacy which may constitute one of the cellular substrates for learning and memory. In addition, $\theta$ rhythm is also strongly linked to hippocampal pyramidal cells that code for spatiotemporal aspects of the animal's environment (Huxter et al., 2003). Second, $\alpha$ oscillations are more related to attentional processes by filtering out irrelevant informations and preventing interference from conflicting stimuli (Klimesch, 2012). Finally, $\gamma$ oscillations are modulated by a variety of cognitive processes such as object recognition and working memory (Tiitinen et al., 1993; Yordanova et al., 1997a,b; Herrmann and Mecklinger, 2000; Fries et al., 2001; Debener et al., 2003; Herrmann et al., 2004a,b) and are thought to temporally link distributed cell assemblies from different sources that are processing related informations.

Slow and fast oscillatory activities are not independent. Indeed, slow and fast rhythms interact with each other, the phase of slow oscillations (mainly $\theta$ rhythm) being able to modulate the amplitude of fast oscillations ( $\beta$ and $\gamma$ rhythms). This phenomenon, known as CFC, is positively associated with cognitive processes in humans (Canolty et al., 2006; Händel and Haarmeier, 2009; Axmacher et al., 2010), monkeys (Canolty et al., 2010), rats (Tort et al., 2008, 2009) and mice (Wulff et al., 2009). More specifically, it is hypothesized that at fast frequencies, CFC would allow distributed brain regions to be synchronized (using the slow one as a "carrier"), which consequently facilitates communication.

Given the key role played by oscillatory activities on cognitive processes such as memory, numerous studies have closely looked at brain oscillatory alterations in AD patients, as well as in animal models of the pathology. In the next parts of this article, we will review recent findings on oscillatory activity alterations in the time course of $\mathrm{AD}$.

\section{OSCILLATORY ACTIVITY IN MILD COGNITIVE IMPAIRMENT (MCI) AND AD PATIENTS}

More than 980 articles in the last 40 years have looked at EEG activity in mild cognitive impairment (MCI) and/or AD patients. Indeed, with the development of new analytic methods that can account for different confounding results (for example, volume conduction), EEG activity seems sensitive enough for an early detection of preclinical $\mathrm{AD}$ and predictive of future conversion from MCI to AD.

The majority of studies focusing on EEG characterization in $\mathrm{AD}$ patients have been done using resting state paradigms. Resting state EEG corresponds to recordings performed in the motionless subject with eyes closed. This task is a fully standardized procedure and can therefore be done in highly comparable experimental conditions. Compared to age-matched healthy control subjects, both MCI and AD patients exhibit an 
increase in relative power of slow oscillations ( $\delta$ and $\theta$ rhythms) associated with a decrease in relative power of fast oscillations ( $\alpha, \beta$, and $\gamma$ rhythms; van der Hiele et al., 2007; Czigler et al., 2008; Moretti et al., 2010). The relative amplitude of $\theta$ oscillations has been proposed as a marker for $\mathrm{AD}$ as it allows the correct classification of $85 \%$ of MCI subjects, distinguishing the ones who progress to clinically manifested $\mathrm{AD}$ from those who remain stable (Jelic et al., 2000). Furthermore, increased $\theta$ power is already present in subjects with subjective complaints 7 years before decline to the MCI state (Prichep et al., 2006).

However, differences in resting state EEG might not be specific to $\mathrm{AD}$. Indeed, multiple types of dementia could also be characterized by similar global network alterations. As an example, an increase in relative $\theta$ power is also found in dementia with Lewy bodies (Kai et al., 2005) and a decrease in relative $\gamma$ power is also found in normal aging, after a brain injury or a stroke (Herrmann and Demiralp, 2005).

Therefore, and to achieve higher specificity, it could be suitable to combine behavioral paradigms in real time with electrophysiological recordings. During behavioral tasks, memory-related activation reveals specific EEG functional differences between MCI patients and control ones that facilitates the early diagnostic of probable AD. As an example, haptic tasks are sensitive to early perceptive-cognitive and functional deficits in MCI patients. Indeed, during tactile tasks, $\theta$-power over right occipital regions is a suitable marker to distinguish healthy subjects from MCI patients (Grunwald et al., 2002). In addition, in a face-name encoding mnemonic task, the recording of EEG alterations is associated with the Mini-Mental State Examination and may serve as a clinically valuable marker for disease severity (Garn et al., 2014).

However, multiple forms of memory are affected in $\mathrm{AD}$ (Didic et al., 2011) and episodic memory impairment is not specific to $\mathrm{AD}$ but is also found in other types of dementia and psychiatric disorders. It was proposed that navigation deficits could help to distinguish patients at higher risk of developing $\mathrm{AD}$ from individuals with normal cognitive aging and those with other neurodegenerative diseases (Lithfous et al., 2013). Indeed, spatial disorientation is already present at MCI and early AD stages. Specific spatial tasks in both virtual or real world paradigms may possibly predict the conversion from normal aging to MCI and from MCI to dementia (Kalová et al., 2005; Laczó et al., 2011; Weniger et al., 2011; Moodley et al., 2015). Spatial navigation depends on $\theta$ (Cornwell et al., 2008; Jacobs et al., 2010; Snider et al., 2013) and $\gamma$ (Park et al., 2014) oscillations. Therefore, behavioral assessments of spatial memory processes combined with EEG techniques might represent a promising strategy for an early detection of preclinical $\mathrm{AD}$ with a high specificity.

\section{OSCILLATORY ACTIVITY IN ANIMAL MODELS OF AD}

In spite of the considerable restriction that few spontaneous animal models recapitulate the entire spectrum of the sporadic form of AD (Strittmatter et al., 1993; Giannakopoulos et al., 1997; Inestrosa et al., 2005; Bons et al., 2006; Toledano et al.,
2014; Stefanova et al., 2014, 2015), parallel research on animals has provided an essential contribution in understanding the mechanisms underlying abnormal oscillatory patterns in AD.

Hippocampal slices preparations from rodents and transgenic mice models of $\mathrm{AD}$ constitutes a useful tool for investigating mammalian synaptic alterations during amyloid pathology (Mathis et al., 2011; Hazra et al., 2013). However, spontaneous oscillations are not present in hippocampal slices. Indeed, hippocampal oscillatory activity is the product of multiple intra- and extra-hippocampal oscillators (the hippocampus and the medial septum for $\theta$ oscillations; Borisyuk et al., 1999; Denham and Borisyuk, 2000; Wang, 2002; Goutagny et al., 2009) and an intra-hippocampal excitation/inhibition loop, together with inputs from the entorhinal cortex for $\gamma$ rhythms (Bragin et al., 1995). The study of hippocampal oscillations in slices requires the application of a cholinergic or glutamatergic (kainate receptor) agonist to increase cellular excitability. With such a type of approach, it was shown that application of $\mathrm{A} \beta_{1-42}$ reduced the power of kainate-induced $\gamma$ oscillations in mice (Kurudenkandy et al., 2014). However, the utility of these models must be considered in light of how well they mimic the actual phenomenon. A bath application of carbachol to hippocampal slices can generate either $\theta$ or $\gamma$ rhythms depending on experimental parameters such as: slice orientation, thickness, drug concentration, and temperature (Konopacki et al., 1987; Fisahn et al., 1998; Fellous and Sejnowski, 2000). However, there is no evidence that in freely moving animals $\theta$ and $\gamma$ rhythms require cholinergic neurotransmission. Another popular model of hippocampal $\gamma$ rhythms uses kainite receptor activation (Traub et al., 2005). Once again, although robust $\gamma$ can be observed in hippocampal preparations, it does not appear as though in vivo $\gamma$ rhythms are mediated by kainate receptors. Only one report has generated a model of simultaneous $\theta$ and $\gamma$ rhythms in the presence of kainic acid (Gloveli et al., 2005) which required a unique hippocampal slice containing transverse and longitudinal circuitries. The recent development of a new in vitro preparation, which respects the complex three-dimensional organization of intrinsic hippocampal circuits, has circumvented most of the issues aforementioned. Using this preparation, it is possible to characterize spontaneously occurring $\theta$ (Goutagny et al., 2009) and $\gamma$ (Jackson et al., 2011) oscillations. In a transgenic mouse model of AD, the TgCRND8 mice, hippocampal $\theta-\gamma$ uncoupling was shown to precede soluble $\mathrm{A} \beta$ and plaque accumulation (Goutagny et al., 2013).

Oscillatory activities can also be measured in anesthetized animals (Xu et al., 2015). In this paradigm, $\theta$ oscillations can be recorded under urethane anesthesia either spontaneously or after sensory stimulation (tail or paw pinches) or electric stimulation of the brainstem nucleus pontis oralis (Bland and Whishaw, 1976). With this approach, it was shown that APP/PS1 transgenic mice showed an age-dependent decrease in hippocampal $\theta$ activity correlating with plaque load (Scott et al., 2012). However, under urethane anesthesia, $\theta$ oscillations are exclusively of type II (atropine-sensitive) and no type I $\theta$ (atropine-resistant) is present (Kramis et al., 1975). Therefore, in order to fully capture possible alterations in hippocampal oscillatory activity in animal models of $\mathrm{AD}$, recordings in freely moving animals are required. 
Many cognitive paradigms used in MCI and early $\mathrm{AD}$ diagnoses are based on verbal episodic memory tasks that present a translational problem for animal studies. Indeed, episodic memory, which is characterized by conscious recollection of context-rich events, is rather difficult to probe in animals. Several episodic-memory-like paradigms are currently being developed in rodents and apes but their extrapolation and dependence on a similar set of temporal lobe structures than human episodic memory still need to be confirmed. Fortunately, nature knows best, the hippocampus and the parahippocampal formation, responsible for episodic memory in humans, seem to have anatomical and functional homologs across mammal species. As an example, these brain regions are implicated in the encoding and retrieval of information related to environment during spatial navigation in rodents (Molter et al., 2012). In a recent study, rhesus monkeys learned how to freely drive a wheelchair to navigate through a complex maze, providing a strong support for an electrophysiological investigation of spatial navigation in the real world (Etienne et al., 2014). In rodents as in humans, spatial representations are related to modulation of $\theta$ oscillations as well as $\theta-\gamma$ coupling (Huxter et al., 2003; Bott et al., 2015). Interestingly, in a transgenic mouse model of $\mathrm{AD}$, the Tg5xFAD mice, a decrease of $\theta$ and $\gamma$ frequencies precedes disturbances in learning performances in a navigation task (Schneider et al., 2014).

\section{CONCLUSION}

To conclude, with the support of the previously described results obtained both on animal models and patients, we propose that CFC alterations might constitute a promising early biomarker of

\section{REFERENCES}

Axmacher, N., Henseler, M. M., Jensen, O., Weinreich, I., Elger, C. E., and Fell, J. (2010). Cross-frequency coupling supports multi-item working memory in the human hippocampus. Proc. Natl. Acad. Sci. U.S.A. 107, 3228-3233. doi: 10.1073/pnas.0911531107

Bland, B. H., and Whishaw, I. Q. (1976). Generators and topography of hippocampal theta (RSA) in the anaesthetized and freely moving rat. Brain Res. 118, 259-280. doi: 10.1016/0006-8993(76)90711-3

Bons, N., Rieger, F., Prudhomme, D., Fisher, A., and Krause, K.-H. (2006). Microcebus murinus: a useful primate model for human cerebral aging and Alzheimer's disease? Genes Brain Behav. 5, 120-130. doi: 10.1111/j.1601183X.2005.00149.x

Borisyuk, R., Denham, M., Denham, S., and Hoppensteadt, F. (1999). Computational models of predictive and memory-related functions of the hippocampus. Rev. Neurosci. 10, 213-232. doi: 10.1515/REVNEURO.1999.10.34.213

Bott, J.-B., Muller, M.-A., Jackson, J., Aubert, J., Cassel, J.-C., Mathis, C., et al. (2015). Spatial reference memory is associated with modulation of theta-gamma coupling in the dentate gyrus. Cereb. Cortex doi: 10.1093/cercor/bhv177 [Epub ahead of print].

Bragin, A., Jandó, G., Nádasdy, Z., Hetke, J., Wise, K., and Buzsáki, G. (1995). Gamma $(40-100 \mathrm{~Hz})$ oscillation in the hippocampus of the behaving rat. J. Neurosci. 15, 47-60.

Canolty, R. T., Edwards, E., Dalal, S. S., Soltani, M., Nagarajan, S. S., Kirsch, H. E., et al. (2006). High gamma power is phase-locked to theta oscillations in human neocortex. Science 313, 1626-1628. doi: 10.1126/science.1128115
AD. Indeed, modifications in hippocampal $\theta-\gamma$ coupling during spatial navigation might occur in the very first stages of $A D$ and serve as a possible predictor for the pathology (Goutagny and Krantic, 2013). Future research aimed at identifying biomarkers based on combined EEG and behavioral testing approaches should integrate the fact that spatial navigation memory tasks used to diagnose $\mathrm{AD}$ in patients can be transposed to animals. In this way, animal studies leave the door open on diagnostic and therapeutic pathways that could be transposable in patients. Moreover, independently of progress made on earlier disease targets, it may be assumed that patients diagnosed at the most precocious stage of the pathology still have enough brain plasticity resources to sustain effective responses to therapeutic interventions, including environmental enrichment (Verret et al., 2013; Yeung et al., 2015), to stop the progression of AD or even reverse it.

\section{AUTHOR CONTRIBUTIONS}

VH and RG wrote the review. CM provided critical inputs. $\mathrm{CH}$ and JC helped to correct the manuscript.

\section{ACKNOWLEDGMENTS}

This work was supported by the University of Strasbourg, the Centre National de la Recherche Scientifique (CNRS) and by grants from the Fondation Fyssen, the European Research Executive Agency, the NARSAD young investigator award and Neurex.

Canolty, R. T., Ganguly, K., Kennerley, S. W., Cadieu, C. F., Koepsell, K., Wallis, J. D., et al. (2010). Oscillatory phase coupling coordinates anatomically dispersed functional cell assemblies. Proc. Natl. Acad. Sci. U.S.A. 107, 1735617361. doi: 10.1073/pnas.1008306107

Cornwell, B. R., Johnson, L. L., Holroyd, T., Carver, F. W., and Grillon, C. (2008). Human hippocampal and parahippocampal theta $(\theta)$ during goaldirected spatial navigation predicts performance on a virtual Morris water maze. J. Neurosci. 28, 5983-5990. doi: 10.1523/JNEUROSCI.5001-07.2008

Czigler, B., Csikós, D., Hidasi, Z., Anna Gaál, Z., Csibri, E., Kiss, E., et al. (2008). Quantitative EEG in early Alzheimer's disease patients - power spectrum and complexity features. Int. J. Psychophysiol. 68, 75-80. doi: 10.1016/j.ijpsycho.2007.11.002

Debener, S., Herrmann, C. S., Kranczioch, C., Gembris, D., and Engel, A. K. (2003). Top-down attentional processing enhances auditory evoked gamma band activity. Neuroreport 14, 683-686. doi: 10.1097/01.wnr.0000064987.96259.5c

Denham, M. J., and Borisyuk, R. M. (2000). A model of theta rhythm production in the septal-hippocampal system and its modulation by ascending brain stem pathways. Hippocampus 10, 698-716. doi: 10.1002/10981063(2000)10:6 < 698::AID-HIPO1008> 3.0.CO;2-Z

Didic, M., Barbeau, E. J., Felician, O., Tramoni, E., Guedj, E., Poncet, M., et al. (2011). Which memory system is impaired first in Alzheimer's disease? J. Alzheimers Dis. 27, 11-22. doi: 10.3233/JAD-2011-110557

Etienne, S., Guthrie, M., Goillandeau, M., Nguyen, T. H., Orignac, H., Gross, C., et al. (2014). Easy rider: monkeys learn to drive a wheelchair to navigate through a complex maze. PLoS ONE 9:e96275. doi: 10.1371/journal.pone.0096275

Fellous, J. M., and Sejnowski, T. J. (2000). Cholinergic induction of oscillations in the hippocampal slice in the slow $(0.5-2 \mathrm{~Hz})$, theta $(5-12 \mathrm{~Hz})$, and 
gamma (35-70 Hz) bands. Hippocampus 10, 187-197. doi: 10.1002/(SICI)10981063(2000) 10:2<187::AID-HIPO8> 3.0.CO;2-M

Fisahn, A., Pike, F. G., Buhl, E. H., and Paulsen, O. (1998). Cholinergic induction of network oscillations at $40 \mathrm{~Hz}$ in the hippocampus in vitro. Nature 394, 186-189. doi: $10.1038 / 28179$

Fries, P., Reynolds, J. H., Rorie, A. E., and Desimone, R. (2001). Modulation of oscillatory neuronal synchronization by selective visual attention. Science 291 , 1560-1563. doi: 10.1126/science.291.5508.1560

Garn, H., Waser, M., Deistler, M., Schmidt, R., Dal-Bianco, P., Ransmayr, G., et al. (2014). Quantitative EEG in Alzheimer's disease: cognitive state, resting state and association with disease severity. Int. J. Psychophysiol. 93, 390-397. doi: 10.1016/j.ijpsycho.2014.06.003

Giannakopoulos, P., Silhol, S., Jallageas, V., Mallet, J., Bons, N., Bouras, C., et al. (1997). Quantitative analysis of tau protein-immunoreactive accumulations and beta amyloid protein deposits in the cerebral cortex of the mouse lemur, Microcebus murinus. Acta Neuropathol. (Berl.) 94, 131-139. doi: 10.1007/s004010050684

Gianotti, L. R. R., Künig, G., Lehmann, D., Faber, P. L., Pascual-Marqui, R. D., Kochi, K., et al. (2007). Correlation between disease severity and brain electric LORETA tomography in Alzheimer's disease. Clin. Neurophysiol. 118, 186-196. doi: 10.1016/j.clinph.2006.09.007

Gloveli, T., Dugladze, T., Saha, S., Monyer, H., Heinemann, U., Traub, R. D., et al. (2005). Differential involvement of oriens/pyramidale interneurones in hippocampal network oscillations in vitro. J. Physiol. 562, 131-147. doi: 10.1113/jphysiol.2004.073007

Goutagny, R., Gu, N., Cavanagh, C., Jackson, J., Chabot, J.-G., Quirion, R., et al. (2013). Alterations in hippocampal network oscillations and theta-gamma coupling arise before $A \beta$ overproduction in a mouse model of Alzheimer's disease. Eur. J. Neurosci. 37, 1896-1902. doi: 10.1111/ejn.12233

Goutagny, R., Jackson, J., and Williams, S. (2009). Self-generated theta oscillations in the hippocampus. Nat. Neurosci. 12, 1491-1493. doi: 10.1038/nn.2440

Goutagny, R., and Krantic, S. (2013). Hippocampal oscillatory activity in Alzheimer's disease: toward the identification of early biomarkers? Aging Dis. 4, 134-140.

Grunwald, M., Busse, F., Hensel, A., Riedel-Heller, S., Kruggel, F., Arendt, T., et al. (2002). Theta-power differences in patients with mild cognitive impairment under rest condition and during haptic tasks. Alzheimer Dis. Assoc. Disord. 16, 40-48. doi: 10.1097/00002093-200201000-00006

Händel, B., and Haarmeier, T. (2009). Cross-frequency coupling of brain oscillations indicates the success in visual motion discrimination. Neuroimage 45, 1040-1046. doi: 10.1016/j.neuroimage.2008.12.013

Hardy, J., and Selkoe, D. J. (2002). The amyloid hypothesis of Alzheimer's disease: progress and problems on the road to therapeutics. Science 297, 353-356. doi: 10.1126/science.1072994

Hazra, A., Gu, F., Aulakh, A., Berridge, C., Eriksen, J. L., and Ziburkus, J. (2013). Inhibitory neuron and hippocampal circuit dysfunction in an aged mouse model of Alzheimer's disease. PLoS ONE 8:e64318. doi: 10.1371/journal.pone.0064318

Herrmann, C. S., and Demiralp, T. (2005). Human EEG gamma oscillations in neuropsychiatric disorders. Clin. Neurophysiol. 116, 2719-2733. doi: 10.1016/j.clinph.2005.07.007

Herrmann, C. S., Lenz, D., Junge, S., Busch, N. A., and Maess, B. (2004a). Memory-matches evoke human gamma-responses. BMC Neurosci. 5:13. doi: 10.1186/1471-2202-5-13

Herrmann, C. S., Munk, M. H. J., and Engel, A. K. (2004b). Cognitive functions of gamma-band activity: memory match and utilization. Trends Cogn. Sci. 8, 347-355. doi: 10.1016/j.tics.2004.06.006

Herrmann, C. S., and Mecklinger, A. (2000). Magnetoencephalographic responses to illusory figures: early evoked gamma is affected by processing of stimulus features. Int. J. Psychophysiol. 38, 265-281. doi: 10.1016/S0167-8760(00)00170-7

Huxter, J., Burgess, N., and O'Keefe, J. (2003). Independent rate and temporal coding in hippocampal pyramidal cells. Nature 425, 828-832. doi: 10.1038 /nature 02058

Inestrosa, N. C., Reyes, A. E., Chacón, M. A., Cerpa, W., Villalón, A., Montiel, J., et al. (2005). Human-like rodent amyloid-beta-peptide determines Alzheimer pathology in aged wild-type Octodon degu. Neurobiol. Aging 26, 1023-1028. doi: 10.1016/j.neurobiolaging.2004.09.016
Jackson, J., Goutagny, R., and Williams, S. (2011). Fast and slow $\gamma$ rhythms are intrinsically and independently generated in the subiculum. J. Neurosci. 31, 12104-12117. doi: 10.1523/JNEUROSCI.1370-11.2011

Jacobs, J., Korolev, I. O., Caplan, J. B., Ekstrom, A. D., Litt, B., Baltuch, G., et al. (2010). Right-lateralized brain oscillations in human spatial navigation. J. Cogn. Neurosci. 22, 824-836. doi: 10.1162/jocn.2009.21240

Jelic, V., Johansson, S. E., Almkvist, O., Shigeta, M., Julin, P., Nordberg, A., et al. (2000). Quantitative electroencephalography in mild cognitive impairment: longitudinal changes and possible prediction of Alzheimer's disease. Neurobiol. Aging 21, 533-540. doi: 10.1016/S0197-4580(00)00153-6

Kai, T., Asai, Y., Sakuma, K., Koeda, T., and Nakashima, K. (2005). Quantitative electroencephalogram analysis in dementia with Lewy bodies and Alzheimer's disease. J. Neurol. Sci. 237, 89-95. doi: 10.1016/j.jns.2005.05.017

Kalová, E., Vlcek, K., Jarolímová, E., and Bures, J. (2005). Allothetic orientation and sequential ordering of places is impaired in early stages of Alzheimer's disease: corresponding results in real space tests and computer tests. Behav. Brain Res. 159, 175-186. doi: 10.1016/j.bbr.2004.10.016

Klimesch, W. (2012). $\alpha$-band oscillations, attention, and controlled access to stored information. Trends Cogn. Sci. 16, 606-617. doi: 10.1016/j.tics.2012.10.007

Konopacki, J., MacIver, M. B., Bland, B. H., and Roth, S. H. (1987). Carbacholinduced EEG "theta" activity in hippocampal brain slices. Brain Res. 405, 196-198. doi: 10.1016/0006-8993(87)91009-2

Kramis, R., Vanderwolf, C. H., and Bland, B. H. (1975). Two types of hippocampal rhythmical slow activity in both the rabbit and the rat: relations to behavior and effects of atropine, diethyl ether, urethane, and pentobarbital. Exp. Neurol. 49, 58-85. doi: 10.1016/0014-4886(75)90195-8

Kurudenkandy, F. R., Zilberter, M., Biverstål, H., Presto, J., Honcharenko, D. Strömberg, R., et al. (2014). Amyloid- $\beta$-induced action potential desynchronization and degradation of hippocampal gamma oscillations is prevented by interference with peptide conformation change and aggregation. J. Neurosci. 34, 11416-11425. doi: 10.1523/JNEUROSCI.119514.2014

Laczó, J., Andel, R., Vlček, K., Macoška, V., Vyhnálek, M., Tolar, M., et al. (2011). Spatial navigation and APOE in amnestic mild cognitive impairment. Neurodegener. Dis. 8, 169-177. doi: 10.1159/000321581

Lahiri, D. K., Kotwal, G. J., Farlow, M. R., Sima, A., Kupsky, W., Sarkar, F. H., et al. (2002). The role of the carboxyl-terminal fragments of amyloid precursor protein in Alzheimer's disease. Ann. N. Y. Acad. Sci. 973, 334-339. doi: 10.1111/j.1749-6632.2002.tb04661.x

Lauritzen, I., Pardossi-Piquard, R., Bauer, C., Brigham, E., Abraham, J.-D., Ranaldi, S., et al. (2012). The $\beta$-secretase-derived C-terminal fragment of $\beta A P P, C 99$, but not $A \beta$, is a key contributor to early intraneuronal lesions in triple-transgenic mouse hippocampus. J. Neurosci. 32, 16243-16255. doi: 10.1523/JNEUROSCI.2775-12.2012

Lithfous, S., Dufour, A., and Després, O. (2013). Spatial navigation in normal aging and the prodromal stage of Alzheimer's disease: insights from imaging and behavioral studies. Ageing Res. Rev. 12, 201-213. doi: 10.1016/j.arr.2012.04.007

Mathis, D. M., Furman, J. L., and Norris, C. M. (2011). Preparation of acute hippocampal slices from rats and transgenic mice for the study of synaptic alterations during aging and amyloid pathology. J. Vis. Exp. 23:pii:2330. doi: $10.3791 / 2330$

Mikulca, J. A., Nguyen, V., Gajdosik, D. A., Teklu, S. G., Giunta, E. A., Lessa, E. A., et al. (2014). Potential novel targets for Alzheimer pharmacotherapy: II. Update on secretase inhibitors and related approaches. J. Clin. Pharm. Ther. 39, 25-37. doi: $10.1111 /$ jcpt.12112

Molter, C., O’Neill, J., Yamaguchi, Y., Hirase, H., and Leinekugel, X. (2012). Rhythmic modulation of $\theta$ oscillations supports encoding of spatial and behavioral information in the rat hippocampus. Neuron 75, 889-903. doi: 10.1016/j.neuron.2012.06.036

Moodley, K., Minati, L., Contarino, V., Prioni, S., Wood, R., Cooper, R., et al. (2015). Diagnostic differentiation of mild cognitive impairment due to Alzheimer's disease using a hippocampus-dependent test of spatial memory. Hippocampus 25, 939-951. doi: 10.1002/hipo.22417

Moretti, D. V., Pievani, M., Geroldi, C., Binetti, G., Zanetti, O., Rossini, P. M., et al. (2010). EEG markers discriminate among different subgroup of patients with mild cognitive impairment. Am. J. Alzheimers Dis. Other Demen. 25, 58-73. doi: $10.1177 / 1533317508329814$ 
Palop, J. J., and Mucke, L. (2010). Amyloid- $\beta$ induced neuronal dysfunction in alzheimer's disease: from synapses toward neural networks. Nat. Neurosci. 13, 812-818. doi: 10.1038/nn.2583

Park, J., Lee, H., Kim, T., Park, G. Y., Lee, E. M., Baek, S., et al. (2014). Role of low- and high-frequency oscillations in the human hippocampus for encoding environmental novelty during a spatial navigation task. Hippocampus 24, 13411352. doi: 10.1002/hipo. 22315

Pfurtscheller, G., Zalaudek, K., and Neuper, C. (1998). Event-related beta synchronization after wrist, finger and thumb movement. Electroencephalogr. Clin. Neurophysiol. 109, 154-160. doi: 10.1016/S0924-980X(97) 00070-2

Pimplikar, S. W., Nixon, R. A., Robakis, N. K., Shen, J., and Tsai, L.H. (2010). Amyloid-independent mechanisms in Alzheimer's disease pathogenesis. J. Neurosci. 30, 14946-14954. doi: 10.1523/JNEUROSCI.430510.2010

Price, D. L., Tanzi, R. E., Borchelt, D. R., and Sisodia, S. S. (1998). Alzheimer's disease: genetic studies and transgenic models. Annu. Rev. Genet. 32, 461-493. doi: 10.1146/annurev.genet.32.1.461

Prichep, L. S., John, E. R., Ferris, S. H., Rausch, L., Fang, Z., Cancro, R., et al. (2006). Prediction of longitudinal cognitive decline in normal elderly with subjective complaints using electrophysiological imaging. Neurobiol. Aging 27, 471-481. doi: 10.1016/j.neurobiolaging.2005.07.021

Sauseng, P., Griesmayr, B., Freunberger, R., and Klimesch, W. (2010). Control mechanisms in working memory: a possible function of EEG theta oscillations. Neurosci. Biobehav. Rev. 34, 1015-1022. doi: 10.1016/j.neubiorev.2009.12.006

Schneider, F., Baldauf, K., Wetzel, W., and Reymann, K. G. (2014). Behavioral and EEG changes in male 5xFAD mice. Physiol. Behav. 135, 25-33. doi: 10.1016/j.physbeh.2014.05.041

Scott, L., Feng, J., Kiss, T., Needle, E., Atchison, K., Kawabe, T. T., et al. (2012). Age-dependent disruption in hippocampal $\theta$ oscillation in amyloid$\beta$ overproducing transgenic mice. Neurobiol. Aging 33, 1481.e13-e23. doi: 10.1016/j.neurobiolaging.2011.12.010

Snider, J., Plank, M., Lynch, G., Halgren, E., and Poizner, H. (2013). Human Cortical $\theta$ during free exploration encodes space and predicts subsequent memory. J. Neurosci. 33, 15056-15068. doi: 10.1523/JNEUROSCI.0268-13.2013

Stefanova, N. A., Kozhevnikova, O. S., Vitovtov, A. O., Maksimova, K. Y., Logvinov, S. V., Rudnitskaya, E. A., et al. (2014). Senescence-accelerated OXYS rats: a model of age-related cognitive decline with relevance to abnormalities in Alzheimer disease. Cell Cycle 13, 898-909. doi: 10.4161/cc.28255

Stefanova, N. A., Muraleva, N. A., Korbolina, E. E., Kiseleva, E., Maksimova, K. Y., and Kolosova, N. G. (2015). Amyloid accumulation is a late event in sporadic Alzheimer's disease-like pathology in nontransgenic rats. Oncotarget 6, 1396-1413. doi: 10.18632/oncotarget.2751

Strittmatter, W. J., Saunders, A. M., Schmechel, D., Pericak-Vance, M., Enghild, J., Salvesen, G. S., et al. (1993). Apolipoprotein E: high-avidity binding to beta-amyloid and increased frequency of type 4 allele in late-onset familial Alzheimer disease. Proc. Natl. Acad. Sci. U.S.A. 90, 1977-1981. doi: 10.1073/pnas.90.17.8098

Tamayev, R., Matsuda, S., Arancio, O., and D'Adamio, L. (2012). $\beta$ - but not $\gamma$-secretase proteolysis of APP causes synaptic and memory deficits in a mouse model of dementia. EMBO Mol. Med. 4, 171-179. doi: 10.1002/emmm.201100195

Tiitinen, H., Sinkkonen, J., Reinikainen, K., Alho, K., Lavikainen, J., and Näätänen, R. (1993). Selective attention enhances the auditory 40-Hz transient response in humans. Nature 364, 59-60. doi: 10.1038/364059a0

Toledano, A., Álvarez, M. I., López-Rodríguez, A. B., Toledano-Díaz, A., and Fernández-Verdecia, C. I. (2014). [Does Alzheimer's disease exist in all primates? Alzheimer pathology in non-human primates and its pathophysiological implications (II)]. Neuroligia 29, 42-55. doi: 10.1016/j.nrl.2011.05.004

Tort, A. B. L., Komorowski, R. W., Manns, J. R., Kopell, N. J., and Eichenbaum, H. (2009). Theta-gamma coupling increases during the learning of itemcontext associations. Proc. Natl. Acad. Sci. U.S.A. 106, 20942-20947. doi: 10.1073/pnas.0911331106
Tort, A. B. L., Kramer, M. A., Thorn, C., Gibson, D. J., Kubota, Y., Graybiel, A. M., et al. (2008). Dynamic cross-frequency couplings of local field potential oscillations in rat striatum and hippocampus during performance of a T-maze task. Proc. Natl. Acad. Sci. U.S.A. 105, 20517-20522. doi: 10.1073/pnas.0810524105

Traub, R. D., Bibbig, A., LeBeau, F. E. N., Cunningham, M. O., and Whittington, M. A. (2005). Persistent gamma oscillations in superficial layers of rat auditory neocortex: experiment and model. J. Physiol. 562, 3-8. doi: 10.1113/jphysiol.2004.074641

Van Cauwenberghe, C., Van Broeckhoven, C., and Sleegers, K. (2015). The genetic landscape of Alzheimer disease: clinical implications and perspectives. Genet. Med. doi: 10.1038/gim.2015.117 [Epub ahead of print].

van der Hiele, K., Vein, A. A., van der Welle, A., van der Grond, J., Westendorp, R. G. J., Bollen, E. L. E. M., et al. (2007). EEG and MRI correlates of mild cognitive impairment and Alzheimer's disease. Neurobiol. Aging 28, 1322-1329. doi: 10.1016/j.neurobiolaging.2006.06.006

Verret, L., Krezymon, A., Halley, H., Trouche, S., Zerwas, M., Lazouret, M., et al. (2013). Transient enriched housing before amyloidosis onset sustains cognitive improvement in Tg2576 mice. Neurobiol. Aging 34, 211-225. doi: 10.1016/j.neurobiolaging.2012.05.013

Wang, X.-J. (2002). Pacemaker neurons for the theta rhythm and their synchronization in the septohippocampal reciprocal loop. J. Neurophysiol. 87, 889-900.

Weniger, G., Ruhleder, M., Lange, C., Wolf, S., and Irle, E. (2011). Egocentric and allocentric memory as assessed by virtual reality in individuals with amnestic mild cognitive impairment. Neuropsychologia 49, 518-527. doi: 10.1016/j.neuropsychologia.2010.12.031

Willem, M., Tahirovic, S., Busche, M. A., Ovsepian, S. V., Chafai, M., Kootar, S., et al. (2015). $\eta$-Secretase processing of APP inhibits neuronal activity in the hippocampus. Nature 526, 443-447. doi: 10.1038/nature14864

Womelsdorf, T., Schoffelen, J.-M., Oostenveld, R., Singer, W., Desimone, R., Engel, A. K., et al. (2007). Modulation of neuronal interactions through neuronal synchronization. Science 316, 1609-1612. doi: 10.1126/science.1139597

Wulff, P., Ponomarenko, A. A., Bartos, M., Korotkova, T. M., Fuchs, E. C., Bähner, F., et al. (2009). Hippocampal theta rhythm and its coupling with gamma oscillations require fast inhibition onto parvalbuminpositive interneurons. Proc. Natl. Acad. Sci. U.S.A. 106, 3561-3566. doi: 10.1073/pnas.0813176106

Xu, W., Fitzgerald, S., Nixon, R. A., Levy, E., and Wilson, D. A. (2015). Early hyperactivity in lateral entorhinal cortex is associated with elevated levels of A $\beta$ PP metabolites in the Tg2576 mouse model of Alzheimer's disease. Exp. Neurol. 264, 82-91. doi: 10.1016/j.expneurol.2014.12.008

Yeung, S. T., Martinez-Coria, H., Ager, R. R., Rodriguez-Ortiz, C. J., BagliettoVargas, D., and LaFerla, F. M. (2015). Repeated cognitive stimulation alleviates memory impairments in an Alzheimer's disease mouse model. Brain Res. Bull. 117, 10-15. doi: 10.1016/j.brainresbull.2015.07.001

Yordanova, J., Kolev, V., and Demiralp, T. (1997a). Effects of task variables on the amplitude and phase-locking of auditory gamma band responses in human. Int. J. Neurosci. 92, 241-258. doi: 10.3109/00207459708986404

Yordanova, J., Kolev, V., and Demiralp, T. (1997b). The phase-locking of auditory gamma band responses in humans is sensitive to task processing. Neuroreport 8, 3999-4004. doi: 10.1097/00001756-199712220-00029

Conflict of Interest Statement: The authors declare that the research was conducted in the absence of any commercial or financial relationships that could be construed as a potential conflict of interest.

Copyright (c) 2015 Hamm, Héraud, Cassel, Mathis and Goutagny. This is an openaccess article distributed under the terms of the Creative Commons Attribution License (CC BY). The use, distribution or reproduction in other forums is permitted, provided the original author(s) or licensor are credited and that the original publication in this journal is cited, in accordance with accepted academic practice. No use, distribution or reproduction is permitted which does not comply with these terms. 